\title{
Biomimetic Superhydrophobic Cobalt Blue/Clay Mineral Hybrid Pigments with Self-cleaning Property and Different Colors
}

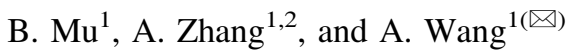 \\ ${ }^{1}$ Key Laboratory of Clay Mineral Applied Research of Gansu Province, \\ Center of Eco-material and Green Chemistry, \\ Lanzhou Institute of Chemical Physics, Chinese Academy of Sciences, \\ Lanzhou 730000, People's Republic of China \\ aqwang@licp.cas.cn \\ 2 Center of Materials Science and Optoelectronics Engineering, \\ University of Chinese Academy of Sciences, Beijing 100049, \\ People's Republic of China
}

\begin{abstract}
Inspired by self-cleaning and water-repellent properties of the lotus leaf, biomimetic superhydrophobic cobalt blue/clay mineral hybrid pigments were facilely fabricated based on the rough surface of hybrid pigments and the modification with various organosilanes. The obtained hybrid pigments were characterized using various analytical techniques. Due to the difference in the compositions and morphologies of clay minerals, the obtained cobalt blue/clay mineral hybrid pigments exhibited different color properties. Superhydrophobicity of hybrid pigments was mainly regulated by the types of organosilanes instead of the morphologies of hybrid pigments. The sprayed coating of the superhydrophobic hybrid pigments exhibited the excellent self-cleaning performance with high water contact angle and low sliding angle. The coatings also presented excellent environmental and chemical durability even under harsh conditions. Therefore, the obtained biomimetic superhydrophobic cobalt blue/clay mineral hybrid pigments may be applied in various fields, such as anticorrosion, self-cleaning coating, etc.
\end{abstract}

Keywords: Biomimetic - Superhydrophobic $\cdot$ Cobalt blue $\cdot$ Clay minerals · Self-cleaning

\section{Introduction}

Cobalt blue (cobalt aluminate, $\mathrm{CoAl}_{2} \mathrm{O}_{4}$ ) pigment is a typical eco-friendly blue inorganic pigment. Due to high refractive index, excellent chemical and thermal stability, it can be widely applied in ceramics, paints, engineering plastics, etc. However, the high cost of $\mathrm{CoAl}_{2} \mathrm{O}_{4}$ pigment severely restrains their relevant applications due to the high price of cobalt compounds and the disadvantages of the traditional solid phase method 
(Armijo 1969). In addition, most of the common application fields of $\mathrm{CoAl}_{2} \mathrm{O}_{4}$ pigment are hydrophilic, which may be easily contaminated by dark liquid, oil stains, blot in our daily life. Therefore, it is very necessary to develop low-cost $\mathrm{CoAl}_{2} \mathrm{O}_{4}$ pigment with and self-cleaning ability.

Inspired by the unique water-repellent surfaces of the lotus leaf in the natural world (Barthlott and Neinhuis 1997), the design of superhydrophobic surfaces has become the focus in both fundamental research and industrial applications by construction of rough surface structure and modification using materials with low surface free energy. Recently, substrate-based inorganic hybrid pigments composed of an inorganic substrate coated with inorganic pigment nanoparticles have attracted increasingly attention. Our groups successfully prepared $\mathrm{CoAl}_{2} \mathrm{O}_{4}$ hybrid pigment after incorporation of different clay minerals (Mu et al. 2015; Zhang et al. 2017). Incorporation of clay minerals greatly decreased the production cost and calcining temperature for formation of spinel $\mathrm{CoAl}_{2} \mathrm{O}_{4}$, as well as preventing from the aggregation of $\mathrm{CoAl}_{2} \mathrm{O}_{4}$ nanoparticles after being uniformly anchored on the surface of clay minerals. Based on the rough surface of the hybrid pigments, it could realize the superhydrophobic modification of hybrid pigments using materials with low surface free energy. In this study, different $\mathrm{CoAl}_{2} \mathrm{O}_{4}$ hybrid pigments derived from kaoline (Kaol), palygorskite (Pal), halloysite (Hal) and montmorillonite (Mt) were prepared and modified using different organosilanes including octyl triethoxysilane (OTES), dodecyl trimethoxysilane (DTMS), hexadecyltriethoxysilane (HTES) and perfluoroctyl trimethoxysilane (PFOTMS), and the effect of the types organosilanes and the morphologies of hybrid pigments on the superhydrophobic properties was comparatively studied.

\section{Methods and Approaches}

Cobalt blue/hybrid pigments were prepared according to the similar procedure reported in our previous study (Zhang et al. 2017). Typically, $2.91 \mathrm{~g}$ of $\mathrm{Co}\left(\mathrm{NO}_{3}\right)_{2} \cdot 6 \mathrm{H}_{2} \mathrm{O}, 7.50 \mathrm{~g}$ of $\mathrm{Al}\left(\mathrm{NO}_{3}\right)_{3} \cdot 9 \mathrm{H}_{2} \mathrm{O}$ and $1.09 \mathrm{~g}$ of clay minerals were added to $50 \mathrm{~mL}$ of water under magnetic stirring at $150 \mathrm{rpm}$ for $30 \mathrm{~min}$, and then $3 \mathrm{M} \mathrm{NaOH}$ was added dropwise into above mixture until the $\mathrm{pH}$ was reached to 10 . The suspension was continuously stirred for $2 \mathrm{~h}$ at room temperature, and then the solid products were collected by centrifugation, washed with water and directly calcined at $1100{ }^{\circ} \mathrm{C}$ for $2 \mathrm{~h}$ with a rate of $10{ }^{\circ} \mathrm{C} / \mathrm{min}$. Next, the superhydrophobic modification of hybrid pigments was conducted in the ammonia saturated ethanol solution (Zhang et al. 2018). $0.54 \mathrm{~g}$ of organosilanes and $1.5 \mathrm{~g}$ of hybrid pigments with different weight ratios were firstly added into $45 \mathrm{~mL}$ above ethanol solution and stirred for $1 \mathrm{~h}$ at room temperature, and then $4.00 \mathrm{~g}$ of water was injected quickly into the solution and stirred for $24 \mathrm{~h}$ at room temperature. The solid products were finally washed with ethanol for three times and dried in an oven at $60{ }^{\circ} \mathrm{C}$. The obtained samples were labeled as clay mineral-HP-organosilanes according to the involved clay minerals and organosilanes. 


\section{Results and Discussion}

Table 1. Color parameters, water contact angle (CA) and sliding angle (SA) of superhydrophobic hybrid pigments before and after being treated at various conditions

\begin{tabular}{|c|c|c|c|c|c|c|}
\hline Samples & Conditions & $\mathrm{L}^{*}$ & $a^{*}$ & $b^{*}$ & $\mathrm{CA} /{ }^{\circ}$ & $\mathrm{SA} /{ }^{\circ}$ \\
\hline \multirow[t]{4}{*}{ Kal-HP-HTES } & - & 38.1 & 2.6 & -63.8 & 164.2 & 1.0 \\
\hline & $98 \% \mathrm{H}_{2} \mathrm{SO}_{4}$ & 37.4 & 2.6 & -63.6 & 163.8 & 1.2 \\
\hline & $3 \mathrm{M} \mathrm{NaOH}$ & 38.1 & 2.6 & -63.8 & 163.3 & 1.3 \\
\hline & UV for 3 days & 38.0 & 2.6 & -63.9 & 164.0 & 1.1 \\
\hline \multirow[t]{4}{*}{ Pal-HP-HTES } & - & 16.2 & -21.1 & -23.5 & 148.1 & 2.4 \\
\hline & $98 \% \mathrm{H}_{2} \mathrm{SO}_{4}$ & 15.8 & -20.8 & -26.2 & 148.2 & 2.3 \\
\hline & $3 \mathrm{M} \mathrm{NaOH}$ & 16.7 & -21.3 & -24.8 & 147.5 & 2.4 \\
\hline & UV for 3 days & 16.9 & -22.2 & -23.3 & 148.3 & 2.4 \\
\hline \multirow[t]{4}{*}{ Hal-HP-HTES } & - & 55.8 & -2.3 & -55.0 & 151.2 & 1.2 \\
\hline & $98 \% \mathrm{H}_{2} \mathrm{SO}_{4}$ & 55.6 & -2.4 & -54.6 & 151.6 & 1.5 \\
\hline & $3 \mathrm{M} \mathrm{NaOH}$ & 55.8 & -2.8 & -53.7 & 151.8 & 1.8 \\
\hline & UV for 3 days & 55.2 & -2.6 & -54.2 & 150.8 & 1.2 \\
\hline \multirow[t]{4}{*}{ Mt-HP-HTES } & - & 24.5 & -21.2 & -32.3 & 156.4 & 3.7 \\
\hline & $98 \% \mathrm{H}_{2} \mathrm{SO}_{4}$ & 23.2 & -21.3 & -33.2 & 155.6 & 3.4 \\
\hline & $3 \mathrm{M} \mathrm{NaOH}$ & 24.6 & -21.4 & -32.7 & 157.5 & 3.1 \\
\hline & UV for 3 days & 21.2 & -20.4 & -30.5 & 154.8 & 3.3 \\
\hline Kal-HP-OTES & - & 38.1 & 2.5 & -63.8 & 135.1 & 4.0 \\
\hline Kal-HP-DTES & - & 38.1 & 2.6 & -63.8 & 151.2 & 3.0 \\
\hline Kal-HP-PFOTMS & - & 38.0 & 2.5 & -63.7 & 165.2 & 2.0 \\
\hline
\end{tabular}

The color parameters, CA and SA of superhydrophobic hybrid pigments before and after being treated at various conditions were summarized in Table 1. It was found that superhydrophobic hybrid pigments derived from different clay minerals presented different color properties (Fig. 1), which might be attributed to the difference in the compositions of clay minerals, especially Fe element. Among the employed clay minerals, the higher content of Fe element was observed in Pal and Mt than Kal and $\mathrm{Hal}$, which decreased the color parameters of hybrid pigments. By contrast, hybrid pigment prepared using Hal exhibited the optimum color properties, and hybrid pigments obtained from Kal came second. In addition, the water contact angle and sliding angle of different hybrid pigments derived from different clay minerals had no obvious difference after being modified using HTES (Fig. 1). Except for Pal-HP-HTES, the values of $\mathrm{CA}$ and $\mathrm{SA}$ of them were higher than $150^{\circ}$ and below $5^{\circ}$, respectively. Although the hybrid pigments were treated at various conditions, the color properties, CA and SA almost kept stable, indicating the excellent environmental and chemical durability. Furthermore, superhydrophobic Kal-HP modified with various organosilanes presented different CA and SA. With the increase in the carbon chain length, the values of SA increased while the SA values decreased. Meanwhile, the incorporation of 
fluorine atom in organosilanes also favored enhancing the superhydrophobic properties of hybrid pigments.

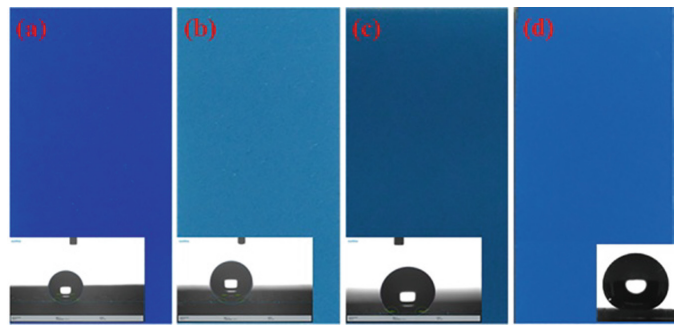

Fig. 1. Digital photos of (a) Hal-HP-HTES, (b) Mt-HP-HTES, (c) APT-HP-HTES and (d) KalHP-HTES

\section{Conclusions}

Superhydrophobic cobalt blue/clay mineral hybrid pigments with self-cleaning property and different colors were successfully prepared by modifying using organosilanes based on the rough surface. The color and superhydrophobicity were closely related to the compositions of clay minerals and the types of organosilanes.

Acknowledgements. The authors are grateful for financial support of the Major Projects of the National Natural Science Foundation of Gansu, China (18JR4RA001), and the Youth Innovation Promotion Association of CAS (2017458).

\section{References}

Armijo JS (1969) The kinetics and mechanism of solid-state spinel formation - a review and critique. Oxid Met 1:171-198

Barthlott W, Neinhuis C (1997) Purity of the sacred lotus, or escape from contamination in biological surfaces. Planta 202:1-8

Mu B, Wang Q, Wang AQ (2015) Effect of different clay minerals and calcination temperature on the morphology and color of clay/CoAl ${ }_{2} \mathrm{O}_{4}$ hybrid pigments. RSC Adv 5:102674-102681

Zhang AJ, Mu B, Luo ZH, Wang AQ (2017) Bright blue halloysite/Co $\mathrm{Al}_{2} \mathrm{O}_{4}$ hybrid pigments: preparation, characterization and application in water-based painting. Dyes Pigm 139:473-481

Zhang AJ, Mu B, Hui AP, Wang AQ (2018) A facile approach to fabricate bright blue heatresisting paint with self-cleaning ability based on $\mathrm{CoAl}_{2} \mathrm{O}_{4} /$ kaoline hybrid pigment. Appl Clay Sci 160:153-161 
Open Access This chapter is licensed under the terms of the Creative Commons Attribution 4.0 International License (http://creativecommons.org/licenses/by/4.0/), which permits use, sharing, adaptation, distribution and reproduction in any medium or format, as long as you give appropriate credit to the original author(s) and the source, provide a link to the Creative Commons license and indicate if changes were made.

The images or other third party material in this chapter are included in the chapter's Creative Commons license, unless indicated otherwise in a credit line to the material. If material is not included in the chapter's Creative Commons license and your intended use is not permitted by statutory regulation or exceeds the permitted use, you will need to obtain permission directly from the copyright holder. 